\section{ESSENTIAL WASTE DISPOSAL FOR USED LATERAL FLOW TESTING KITS}

Initial Medical is one of only a few UK companies currently providing waste disposal for used lateral flow testing kits (COVID-19 tests).

Initial Medical is providing dedicated clear waste bags to customers for all used lateral flow testing kits, with the option of internal containers and external wheelie bins depending on the service required. It is also offering a safe and highly efficient collection and disposal service specifically for this type of waste.

Lateral flow testing kits have been deemed chemical waste by the Department of Health, meaning that they require disposal by incineration in order to protect people's health and the environment. With the vast majority of waste disposal and

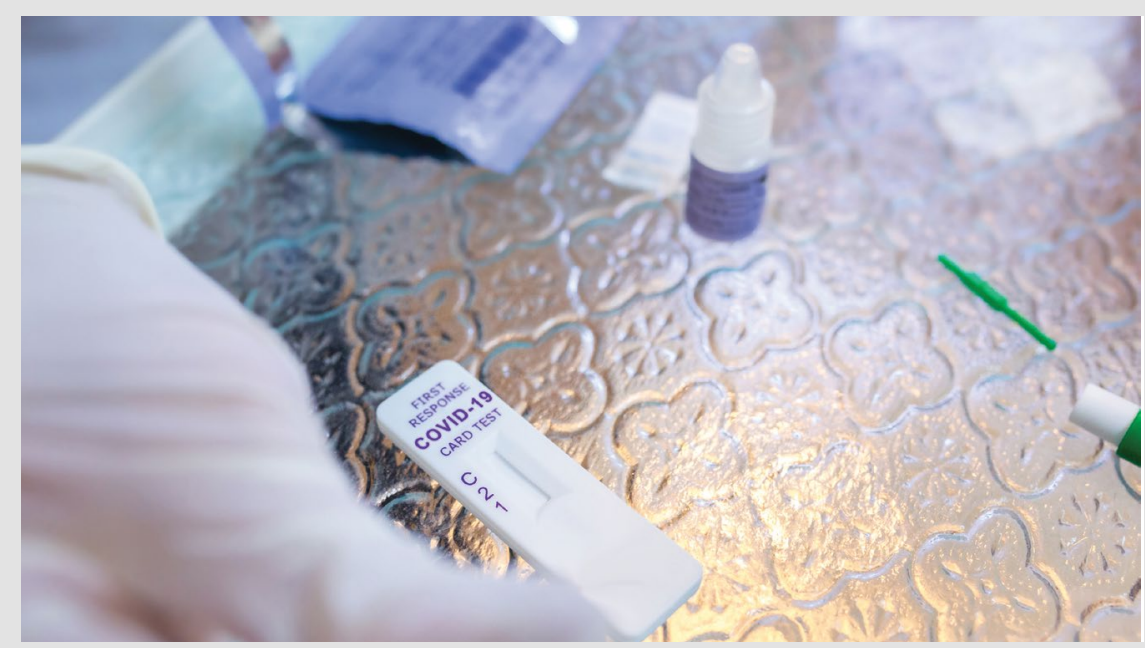

\section{DOING DENTAL SCRAP DIFFERENTLY}

Simple Refining have been in the dental scrap industry a long time, and have seen it all. They won't tell you that they will pay the most, like everybody else. They will say that they have spent years in industry understanding their customer and developing processes that benefit them. With no middleman and an entirely in-house refining process, Simple Refining will get you a payment fast and free within 24 hours. They will send a prepaid, insured envelope to make sure your scrap arrives safely, and provide great value payouts. The Simple Refining team know their customers and go the extra mile to provide a service that sets them apart.

Though their specialism is in Gold treatment centres across the UK currently at capacity due to the extra PPE waste being generated, Initial Medical has secured additional capacity at several disposal sites, to ensure it can help to meet the anticipated demand for the disposal of used lateral flow test kits.

No matter what industry or type of business you're in, if you are utilising lateral flow testing kits to provide COVID-19 testing for your workforce, find out how Initial Medical could support you with the safe and essential disposal of used lateral flow tests.

Find out more by contacting Initial Medical today.

For further information visit initial. co.uk/medical or call 08708504045.

\section{OUTSOURCE PAYROLL FOR EFFICIENCY IN A CHANGING LANDSCAPE}

As dentistry adjusts to Brexit, your practice must support smoother workflows during the transition.

Payroll is one area where outsourcing will save money and time, leaving you free to focus on other areas of the business.

Whether your practice is large or small, Wagemate is a specialist payroll service that will manage everything.

When payroll is in the hands of experts, you will get peace of mind that people will be paid accurately and that you are compliant with HMRC's regulations.

Wagemate is dedicated to client relationships and uses the latest technology to deliver a quality service.

In a shifting landscape, choose Wagemate, the premium payroll provider.

To better manage your payroll, contact payroll specialists Wagemate today, tel: 03330102102 or email info@ wagemate.com.

\section{WHY BUY AN AIR COMPRESSOR WHEN YOU CAN RENT ONE?}

Why buy an air compressor when you can rent one, completely stress-free?

For a fixed rate starting from just $£ 14.95$ per week, Air Supply from DentalAir includes the installation of new equipment that delivers a medical standard sterile air supply and which is compliant to all standards and requirements.

Plus, you will benefit from all service costs included, 24-hour back-up support, a PSSR written scheme and air quality certification for CQC inspection purposes.

Designed by experts, fitted by perfectionists, serviced and supported by professionals - with Air Supply from DentalAir, you can ensure you have sterile air without the stress.

Contact DentalAir at info@dentalair. com or call 08009757530 